\title{
The Influence of Geometrical Dimensions on Electromechanical Performance in Stretchable Circuit
}

\author{
Afiqah Mohd Yunos, ${ }^{1}$ Ghazali Omar, ${ }^{1,2,3 *}$ Husna A. Hamid, ${ }^{1,4}$ \\ Mohd Azli Salim ${ }^{1,2,3}$ and Nor Azmmi Masripan ${ }^{1,2}$ \\ ${ }^{1}$ Faculty of Mechanical Engineering, Universiti Teknikal Malaysia Melaka, \\ Hang Tuah Jaya, 76100 Durian Tunggal, Melaka, Malaysia \\ ${ }^{2}$ Centre for Advanced Research on Energy, Faculty of Mechanical Engineering, \\ Universiti Teknikal Malaysia Melaka, Hang Tuah Jaya, \\ 76100 Durian Tunggal, Melaka, Malaysia \\ ${ }^{3}$ Advanced Manufacturing Centre, Universiti Teknikal Malaysia Melaka, \\ Hang Tuah Jaya, 76100 Durian Tunggal, Melaka, Malaysia \\ ${ }^{4}$ Centre for Research and Innovation Management, Universiti Teknikal Malaysia Melaka, \\ Hang Tuah Jaya, 76100 Durian Tunggal, Melaka, Malaysia \\ *Corresponding author: ghazali@utem.edu.my
}

Published online: 25 August 2020

To cite this article: Yunos, A. M. et al. (2020). The influence of geometrical dimensions on electromechanical performance in stretchable circuit. J. Phys. Sci., 31(2), 75-89. https://doi.org/10.21315/jps2020.31.2.6

To link to this article: https://doi.org/10.21315/jps2020.31.2.6

\begin{abstract}
Stretchable conductive ink (SCI) had been extensively studied for fabricating stretchable electronic devices. In this study, silver conductive ink and thermoplastic polyurethane (TPU) were used as substrate. The ink was printed on the substrate using screen printing with different shaped patterns varied by the widths of $1 \mathrm{~mm}, 2 \mathrm{~mm}$ and $3 \mathrm{~mm}$ : (a) straight, (b) zig-zag, (c) square and (d) sinusoidal. The measurement of resistance was performed using four-point measurement during unloaded and loaded conditions of the shape pattern. This study revealed that width had influenced the resistivity in all shape patterns, where the narrow the width, the higher the resistance is. Comparative studies of electromechanical analysis of the shaped patterns had showed that a $3 \mathrm{~mm}$ width of zig-zag pattern had a better electromechanical performance by having stretchability to maximum of $7.78 \%$. Straight and square shape patterns, however, exhibited the poor tolerate deformation as both failed to conduct electricity upon straining at the minimum elongation of $1.11 \%$.
\end{abstract}

Keywords: Stretchable conductive ink, silver, thermoplastic polyurethane, shape patterns, electromechanical, width 


\section{INTRODUCTION}

Nowadays, the trend among consumers is a noted preference for products with high durability as well as long-term performance. This is driving innovation towards product miniaturisation and encouraging more emerging research in the area of thin and flexible electronics. ${ }^{1,2}$ Coombs and Holden stated that rigid or traditional boards will be replaced by flexible printing boards in a variety of electronic devices. ${ }^{3}$ Conductive circuit is an essential part of printed circuit board (PCB). In recent years, adoption of printing technology in circuit fabrication is becoming a trend. Printing technology such as screen printing, gravure printing and flexography work by bringing the desired pattern directly onto the substrate. ${ }^{4}$ The printing technology is gaining significant interest as it offers many advantages including simple process, affordability, high volume production and less material wastage..$^{5-7}$

Conductive ink and substrate are the main components required in the production of printed circuits. Conductive ink that is stretchable has been studied extensively by previous researchers. ${ }^{8-10}$ The combination of three components which consist of filler, polymer binder and additives, will develop ready-to-use stretchable conductive ink. ${ }^{11}$ Nowadays, conductive fillers such as carbon-based material (graphene, CNT) and metallic material (copper, silver) have been used widely. ${ }^{9,12-14}$ In this study, silver was chosen as the filler since it exhibits properties of the most robust material, excellent conductivity and good chemical durability compared with other materials. ${ }^{10,15}$ Polymer binder acts and serves to hold conductive fillers within the matrix and it offers a stretchability property. Meanwhile, the solvent acts as a carrier by providing a viscosity element for the ink to be printable. Polymerbased substrates, for example, polydimethylsiloxane (PDMS) and polyurethane are among the most desirable existing substrates widely used. Their outstanding properties had drawn a great interest among the researcher due to the boasts economic-friendly process and exhibit a broader design while maintaining their flexibilities which resulted in larger study of intelligent printed electronic (PE) application. ${ }^{16,17}$

To date, material properties including particle content, size and form had played a vital role in affecting both electrical and mechanical performances of the conductive ink. ${ }^{18,19}$ However, when it comes to stretchability, both the conductive ink and the substrate need to be able to withstand several degrees of stretching before losing conductivity, indicating that a printed ink must be free from any defects such as porosity and cracks. On top of that, the usage of metal as an electrical conductor however could create an additional challenge when stretchability is being applied due to the modest bending-mode deformations. ${ }^{20,21}$ Hence, a design strategy focusing on shape pattern for flexibility purposes were briefly studied. ${ }^{22-24}$ 
However, for silver conductive ink, there are scant and very limited study in the literature, especially on the stretchable type of deformation. ${ }^{22}$ For this reason, authors are motivated to understand the optimum geometrical design required for silver conductive ink. In this current research, comparative evaluation on different geometry shape design and electromechanical evaluation were studied.

\section{EXPERIMENTAL}

\subsection{Materials}

Thermoplastic polyurethane (TPU) was supplied by Takeda Sangyo, Japan. The material exhibited a thickness of $100 \mu \mathrm{m}$ with an optically transparent polyester film. The TPU has physical properties of low hardness and over 500\% elasticity. Silver conductive paste was purchased from Mechanic, Hong Kong. The silver content is approximately $67 \mathrm{wt} \%$ with particle size in the range from $1 \mu \mathrm{m}$ to $10 \mu \mathrm{m}$.

\subsection{Test Samples and Patterns}

Printing of ink was carried out by direct stencil print method. TPU was cleaned with acetone (Merck, Malaysia) prior to use. Post-treatment step of printed ink was conducted by curing in the oven at a fixed temperature at $100^{\circ} \mathrm{C}$ for $30 \mathrm{~min}$. The prepared test patterns are showed in Figure 1. All the patterns were varied by widths of $1 \mathrm{~mm}, 2 \mathrm{~mm}$, and $3 \mathrm{~mm}$, respectively.

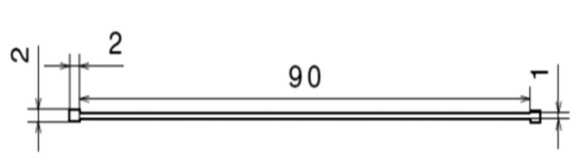

(a)

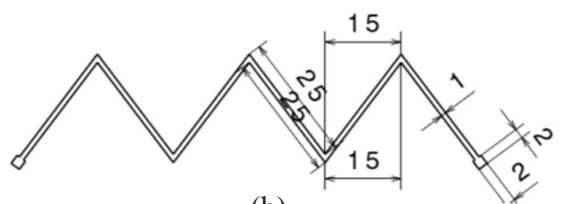

(b)

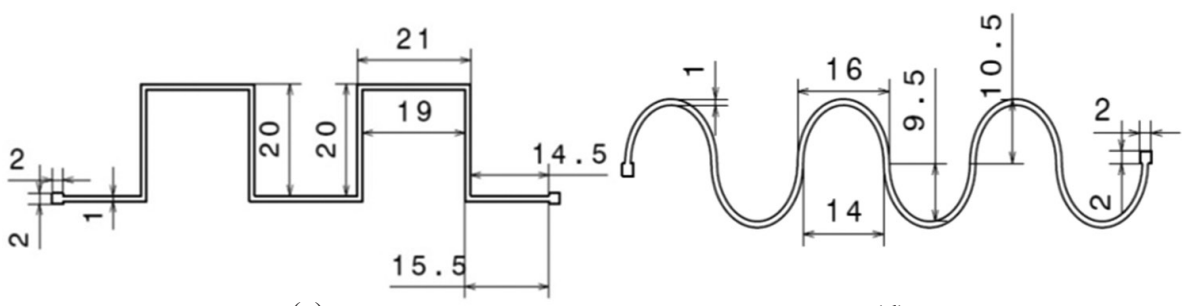

(c)

(d)

Figure 1: Shape and dimensions of shape patterns: (a) straight, (b) zig-zag, (c) square, and (d) sinusoidal (all dimensions are in $\mathrm{mm}$ ). 


\subsection{Nanoindentation Analysis}

Nanoindentation was conducted to analyse the mechanical properties of printed silver. Measurement was performed on the specimen using a DUH-211S Dynamic Ultra Micro Hardness Tester, Shimadzu, Japan. A small diamond tip was loaded into the sample and its distance travelled was measured.

\subsection{Microstructure Analysis}

Scanning electron microscopy (SEM) was used to observe the microstructure behaviour of the printed silver with respect to temperature. The micrograph of SEM was acquired using a JEOL JSM-6010PLUS/LV (Japan) at an accelerated voltage of $10 \mathrm{kV}$.

\subsection{Electromechanical Measurements}

Electromechanical analysis was carried out by measuring resistivity during stretching. Each sample was strained until the conductivity was lost. During the stretching process, several requirements were carefully observed. The holder should be still to support the TPU which is thin and flexible. The initial length of the printed pattern was recorded by marking each end point before the stretching was performed. Meanwhile, the initial mark was drawn on the supporter with the same initial distance of printed pattern. New lines were drawn with distance gaps of $0.1 \mathrm{~cm}$ between each of them, which indicated the elongation distance that the printed pattern was stretched accordingly. One end of the substrate was taped to fix the position on the supporter, and the other end was carefully stretched, making sure that the marked line on the printed pattern stretched according to the elongation distance, which had been marked on the supporter. The above-described stretching procedure was illustrated in Figure 2.

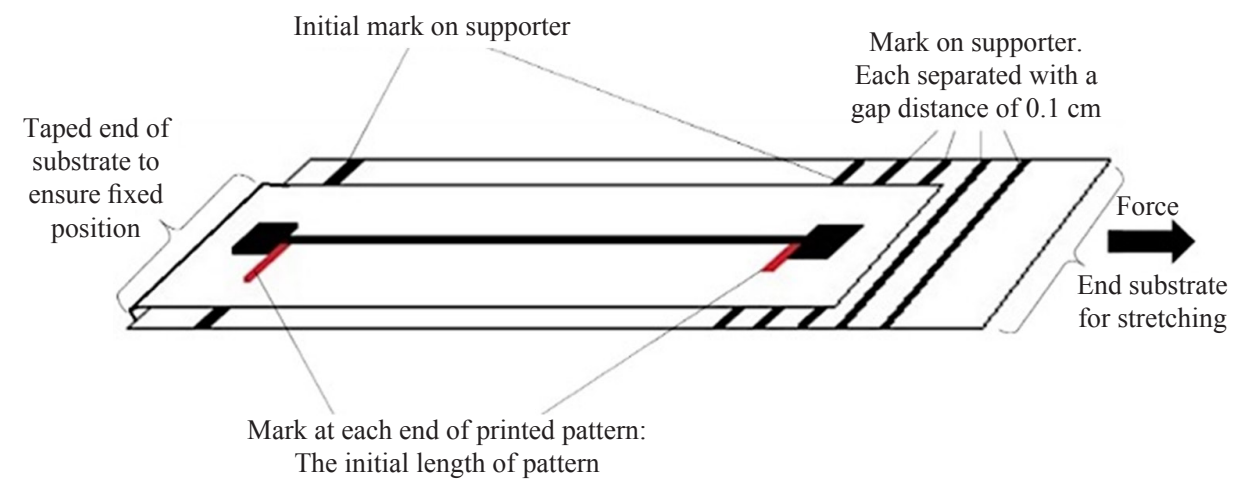

Figure 2: The illustration of stretching procedure. 
The resistance of each pattern was measured using a four-probe configuration. A $10 \mathrm{~mA}$ current was supplied through two outer contacts by connecting alligator clips at each end of the pattern. The voltage was then measured between two inner contacts using two probes with accurate digital multimeter, Keysight Technology, California, United States. The resistance was calculated by inputting the measured voltage results into Equation 1:

$$
R_{i}=\frac{V}{I}
$$

where $R_{i}$ is the calculated initial resistance, $V$ is a voltage between inner probes, and $I$ is the applied current. Then, the calculated resistance was divided by the total line length of each shape pattern according to Equation 2 to ignore the influence of the length:

$$
R=\frac{R_{i}}{l}
$$

where $R$ is the resistance per unit length of shape pattern, $R_{i}$ is calculated from Equation 1, and $l$ is the total length of the shape pattern. Measurement was conducted on each pattern during the unloaded and loaded condition (stretching until conductivity was lost) at: (1) total length of pattern; and (2) the length between two points of curvature zone that were parallel to the stretching force.

\section{RESULTS AND DISCUSSION}

The typical loading-unloading curves of force versus penetration depth of printed silver at room temperature and after being cured at $100^{\circ} \mathrm{C}$ was plotted and showed in Figure 3(a). The curve gives a clear view that silver cured at $100^{\circ} \mathrm{C}$ required a lower load in order to penetrate the sample due to the hardness of silver getting lowered to $\mathrm{HV}=0.182$ compared to the hardness of silver at room temperature $(\mathrm{HV}=3.487)$. The cured elastic moduli at $100^{\circ} \mathrm{C}$ was noted at $9.82 \mathrm{MPa}$ which is much lower compared to room temperature $(428.3 \mathrm{MPa})$. At the temperature of $100^{\circ} \mathrm{C}$, the cured silver was able to undergo an elastic deformation under load applied and it is correlated well with its microstructure behaviour. Figures 3(b) and $3(\mathrm{c})$ showed the micrograph of cured silver at room temperature and $100^{\circ} \mathrm{C}$ respectively. It was noted that small particles distribution was lower when heat was applied. This indicates the diffusion between the particles that took place had led to the formation of larger size particles which changed the mechanical properties from harder to softer. The size of the particles did not show a dramatic increase due to being micro-sized, hence possessing a low surface contact area that 
hindered the diffusion of particles to occur efficiently despite the thermal input supplied. This microstructure behaviour differed in contradiction to nano-sized particles. Generally, diffusion is more active due to the higher surface contact area, hence allowing nano-sized particles to dramatically increase in size whenever it gets exposed to a slight change of temperature. ${ }^{25}$ From the data compiled, it was deduced that temperature plays a significant role in determining the mechanical properties.

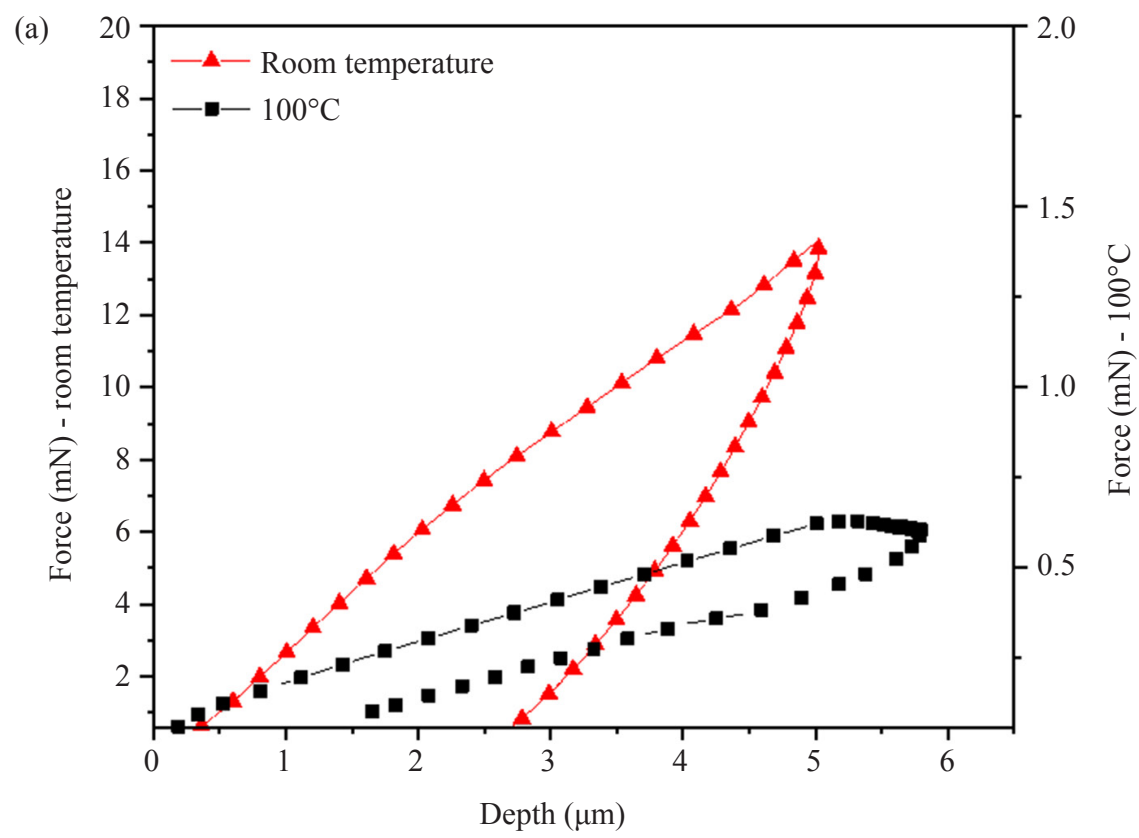

(b)

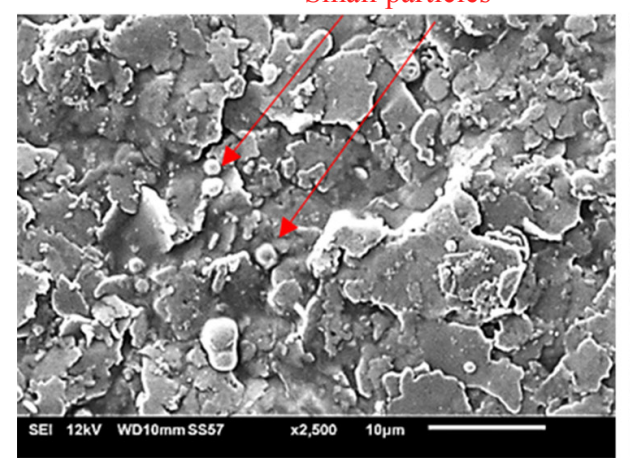

(c)

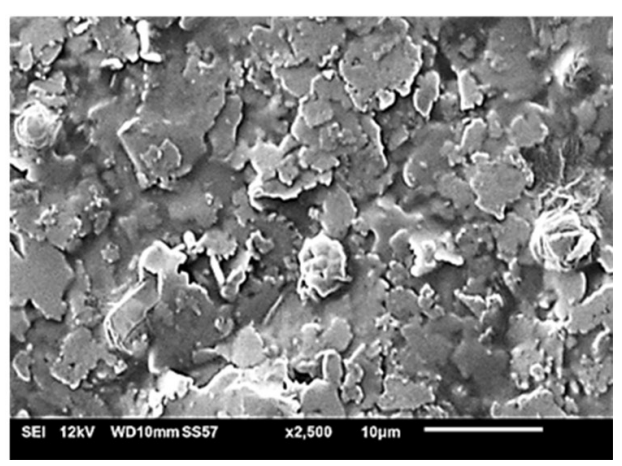

Figure 3: Illustration of (a) force-displacement of printed silver at different curing temperature, and micrograph of printed silver at (b) room temperature, and (c) $100^{\circ} \mathrm{C}$. 
Figure 4 demonstrates the initial resistance of all patterned circuits (straight, square, sinusoidal and zig-zag) approximately ranged between $0.03 \mathrm{~m} \Omega \mathrm{cm}^{-1}$ and $0.20 \mathrm{~m} \Omega \mathrm{cm}^{-1}$. All the patterns exhibited the same trend patterns, where the resistance decreases when the width increases. This is due to the grain boundary and surface scattering effect. Previous study had investigated the dimension (width, thickness) dependence on electrical resistivity of the thin metal film and the behaviour of microstructural in the films. ${ }^{26,27}$ The studies concluded that a reduction of the grain size creating obstacles in transporting electrons due to scattering, hence leading to an increase in resistance. Fine grains appeared on smaller width metal meanwhile large grains were found and grow on wider width metal. ${ }^{27}$ This occurs during the annealing process, where the wider line or trench allowed smaller $\mathrm{Cu}$ grains to grow into a larger size easily, hence causing the presence of larger grain microstructure on the wider width metal, as discussed by Hu et al. ${ }^{28}$

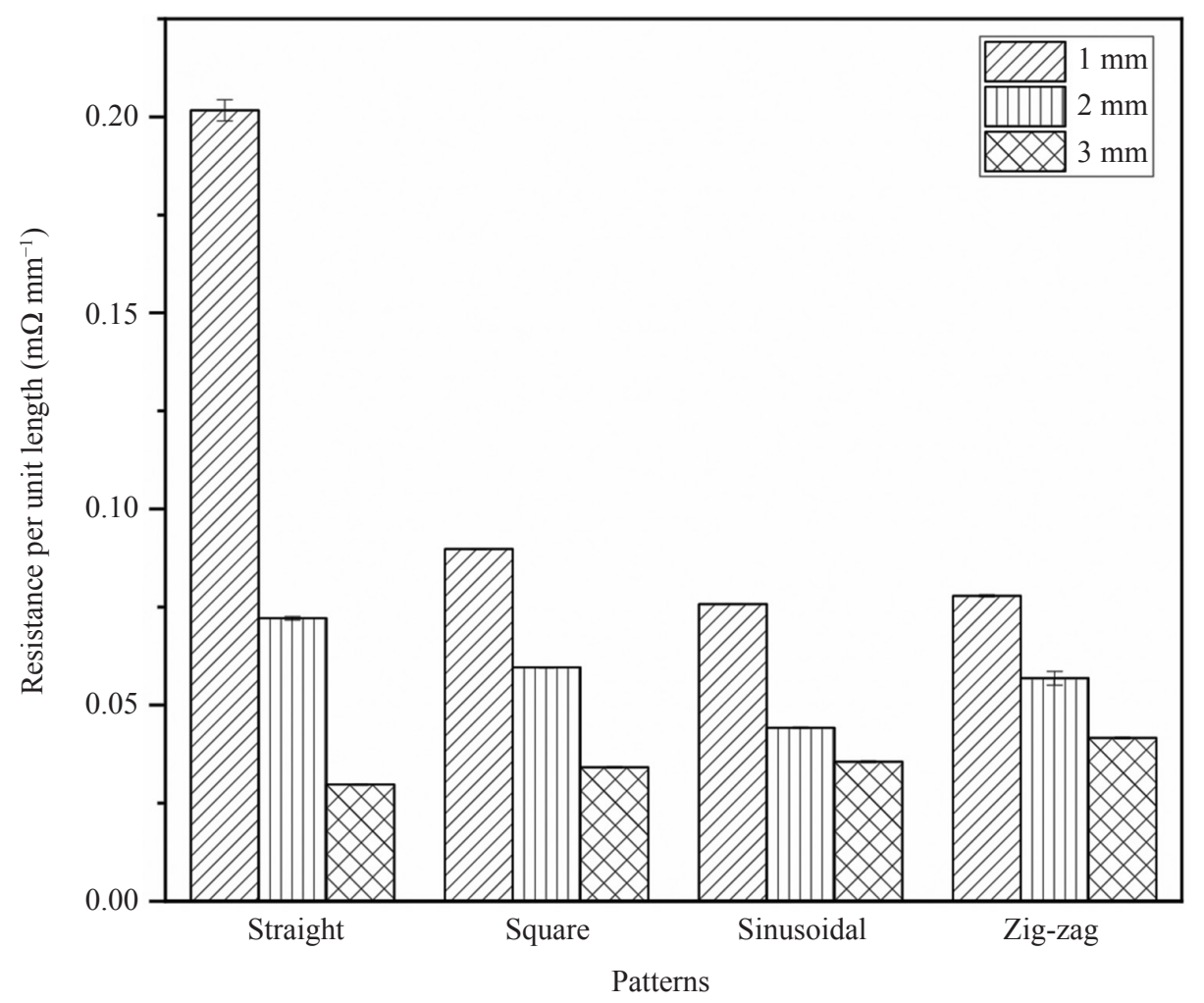

Figure 4: Effect of width on initial resistance during the unloaded condition. 
Figure 5 shows the effect of shape pattern and width on initial and final resistance as well as maximum strain before failure. The maximum straining shown by each shape pattern indicates its failure to withstand any further elasticity and hence exhibited plastic deformation. It was expressed by the appearance of cracks formation, which restricted the currents from passing along the printed pattern causing electrical conductivity to drop. Generally, cracking of the pattern was caused by the strain localisation as the pattern experienced first necking state within a narrow region of the pattern. Large strain or force was accumulated at the necking region of the pattern while other regions experience only a small force. The excessive strain led towards the ruptures at the region. In addition, the length and cross-sectional area of the pattern were played a significant role in determining the resistance change. When stretching was performed, the length and cross-sectional area of the printed pattern were changed to longer and smaller respectively and resulted in decreasing in electrical conductivity performances as resistance was increased. This effect was predicted given the assumption that the resistivity of printed pattern, $\rho$ remains unchanged but the pattern was experiencing smaller volumetric strain corresponding to the continuous stretching. ${ }^{29}$

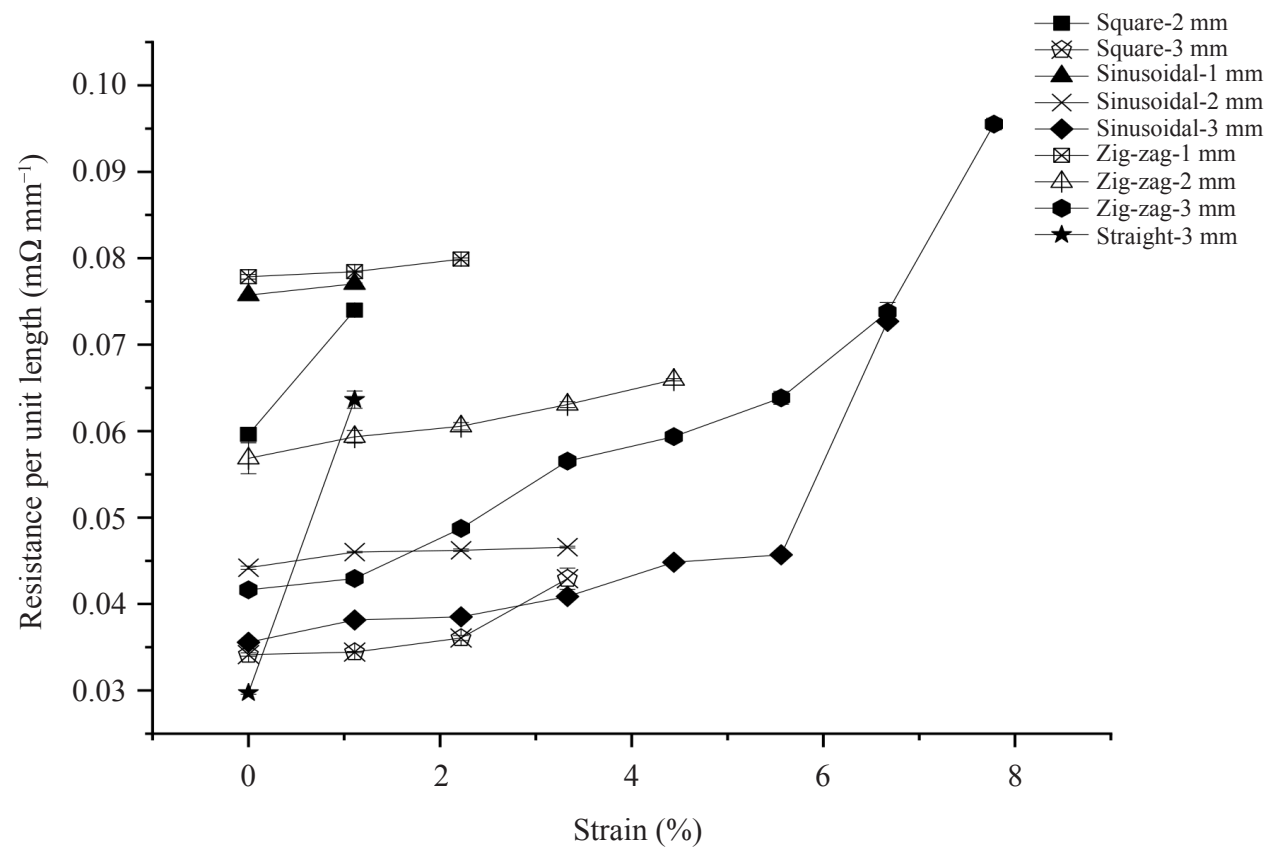

Figure 5: Effect of shape pattern and width on initial and final resistance as well as maximum strain before failure. 
Table 1 depicts the maximum strain percentage experienced by each shape pattern before losing its conductivity. The patterns with broader width were able to withstand larger straining force before it lost its conductivity. The results showed that $1 \mathrm{~mm}$ width for all shapes was only capable for withstanding a minimum elongation of $1.11 \%$ and $2.22 \%$ for sinusoidal and zig-zag, respectively, while both straight and square shapes immediately failed to conduct any electricity when minimum stretching was applied. However, when the width was increased, the capability to withstand stretching was increased. For instance, $3 \mathrm{~mm}$ width of sinusoidal and zig-zag were able to withstand up to $6.67 \%$ and $7.78 \%$ of stretching respectively due to the developed cracks was traversed to the full width of the line patterns (Figures 6 and 7). The fractures in the small width patterns had spread for the full width due to the small area, hence restricting the electrical flow along the pattern was observed. For large width case, small fractures did not individually span the width of the circuit; instead, the fractures were spread out all over a large area. Hence, the conduction could still take place around the edges.

Table 1: The maximum strain percentage experienced by each shape pattern before losing its conductivity.

\begin{tabular}{lccc}
\hline & \multicolumn{3}{c}{ Width $(\mathrm{mm})$} \\
\cline { 2 - 4 } Pattern & \multicolumn{3}{c}{ Maximum strain (\%) } \\
\cline { 2 - 4 } & \multicolumn{3}{c}{3} \\
\hline Straight & - & - & 1.11 \\
Square & - & 1.11 & 3.33 \\
Sinusoidal & 1.11 & 3.33 & 6.67 \\
Zig-zag & 2.22 & 4.44 & 7.78 \\
\hline
\end{tabular}

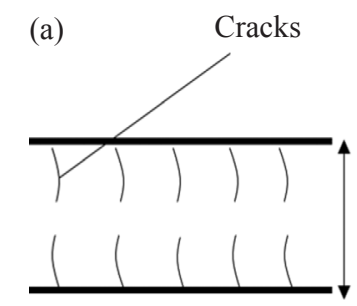

(b)

Figure 6: Schematic illustration of printed shape pattern with the width $a>b$ showing: (a) fracture spread in a long-distance, and (b) fracture spread in short distance. 

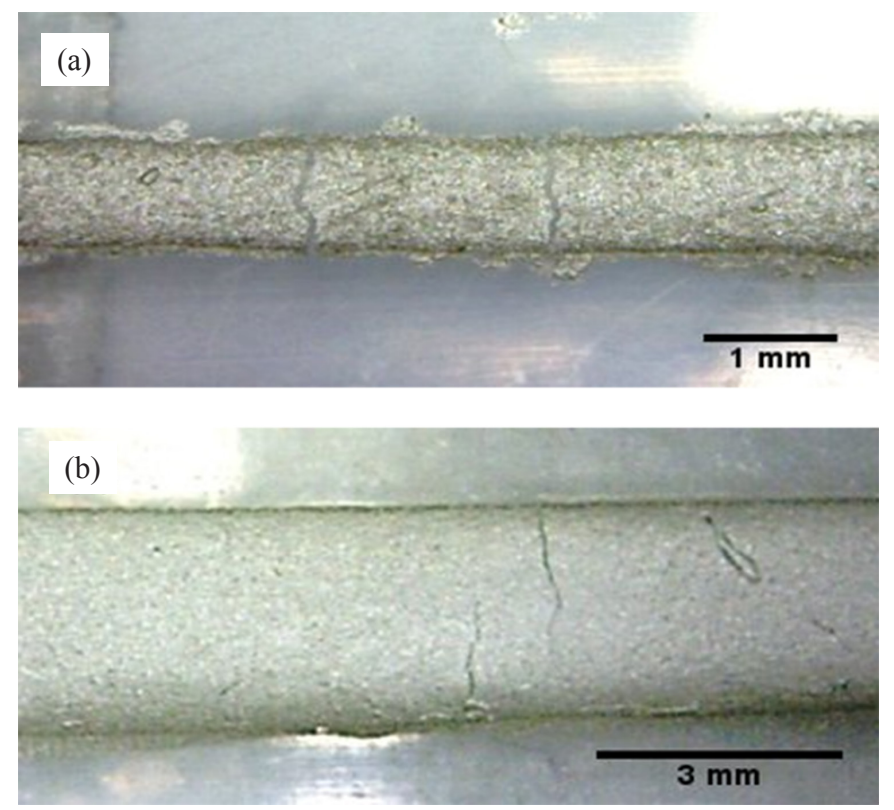

Figure 7: Optical observation on the spread manner of fracture on elongation, showing: (a) fracture spread in short distance manner for $1 \mathrm{~mm}$ width, and (b) fracture spread in a long-distance manner for $3 \mathrm{~mm}$ width.

Besides that, straight and square patterns exhibiting early failure upon lengthening compared to sinusoidal and zig-zag patterns. Both $1 \mathrm{~mm}$ and $2 \mathrm{~mm}$ widths of the straight patterns test samples immediately failed to conduct electricity when minimum stretching applied, however, the sample with $3 \mathrm{~mm}$ width could tolerate stretching up to a maximum value of $1.11 \%$ straining before losing its conductivity. Meanwhile, in the case of square pattern, $1 \mathrm{~mm}$ width also had showed an immediate failures to conduct electricity when minimum stretching was applied, while the samples with $2 \mathrm{~mm}$ and $3 \mathrm{~mm}$ width were able to conduct electricity up to $1.11 \%$ and $3.33 \%$ straining respectively before failure. This contradicts from the previous study by Lacour et al. on the straight $\mathrm{Au}$ line upon straining, which remains conductive before failure at a maximum of $23 \%$ external straining. ${ }^{30}$ Optical observation which had been displayed in Figure 7 explained the reason how the appearance of small cracks at the edge of the stripe when straining initiated the increase of electrical resistance. Continuous straining applied on both square and straight pattern caused the crack to extend more across the width and perpendicularly to its length. These extended cracks behaved as obstacles for the electron to transfer along the line. From the results, it was noted that both straight and square shape patterns were only able to withstand minimum straining force before losing their conductivity. The presence of straight-line zone 
that was parallel to the stretching mode in the designated structure as illustrated in Figure 8 is believed to contribute towards the failure of the pattern to withstand a larger force. This occurrence is described as too high a concentration of stress that exists within the zone parallel to the applied load. In addition, the properties of metal conductors themselves typically have a limited elastic range. Therefore, proper shape design is required in fabricating the conductive circuit in order for the stretching to be possible.

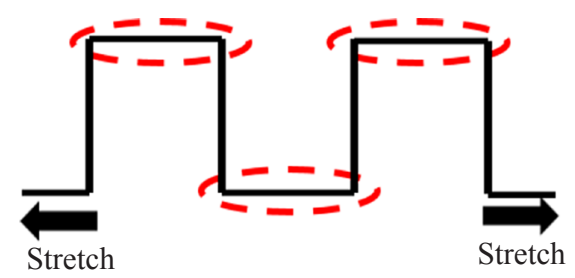

Figure 8: Circles indicate straight-line zone parallel to the stretching mode in structural design of square shape pattern.

The curvature zone of the pattern was believed to play an essential role to determine the capability of pattern to stretch. ${ }^{22,23}$ Figure 9 shows the resistance at the zone parallel to the stretching force when straining was being applied. The zig-zag pattern samples with widths of $1 \mathrm{~mm}, 2 \mathrm{~mm}$ and $3 \mathrm{~mm}$ were able to sustain the highest deformation up to $2.22 \%, 7.78 \% \mathrm{~mm}$ and $11.11 \%$ straining, respectively before losing their conductivity. The results indicate that a curvature zone of zigzag shape with a low curvature radius for all widths exhibited a better tolerance towards elongation compared to sinusoidal. However, Gonzalez et al. showed contradicting results, where a horseshoe shape with bigger curvature radius was reported as the optimal shaper as strain was distributed in the extended part of the shape ${ }^{23}$ The high amplitude contributing towards increasing the maximum strain the line could withstand before failure explains the reason for zig-zag shape in this study can sustain large stretching action even though has a lower radius of curvature compared to sinusoidal. ${ }^{22}$

In addition, a larger width curvature zone had provided a better tolerance towards elongation compared to the narrow width. Figure 10 shows a crack generated in zig-zag pattern upon $2 \mathrm{~mm}$ elongation for samples with width of $1 \mathrm{~mm}$ and $3 \mathrm{~mm}$. The formation of crack was a significant effect on the conductivity performance of the patterns. The larger size of crack developed lead to the higher the resistivity. However, the noted finding was shows disagreement with Gonzalez et al., where narrow width and large radius curvature displayed high tolerance towards deformation. ${ }^{23}$ Apart from that, Abu-Khalaf et al. found that sinusoidal shape pattern with broader width allowed a larger maximum straining compared with 
the narrow one. ${ }^{22}$ However, this observation was not well discussed to clarify the theory, especially in different shape patterns. It is believed that the observation is potentially related to the necking mechanism where larger width would allow the cracks in the necking region to extend in the slow mode across the width hence could tolerate high deformation.

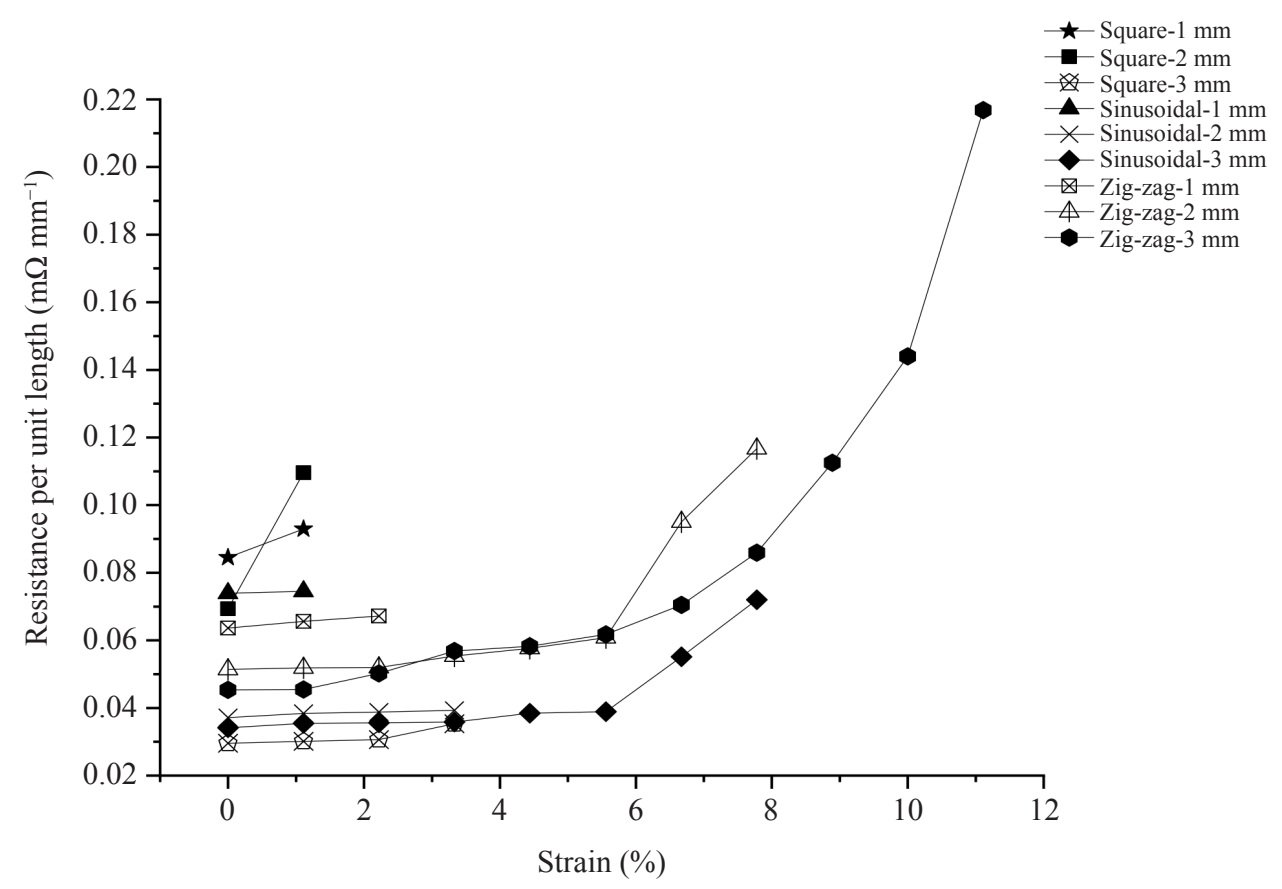

Figure 9: The changes of resistance at the zone parallel to the force when strain was being applied.
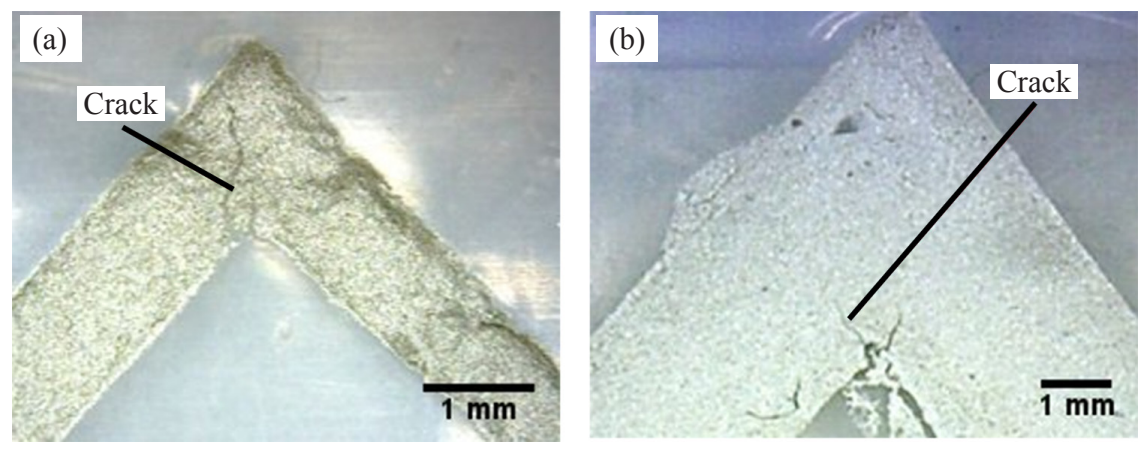

Figure 10: Crack generated in zig-zag pattern upon $2 \mathrm{~mm}$ elongation for sample with: (a) $1 \mathrm{~mm}$ width, and (b) $3 \mathrm{~mm}$ width. 


\section{CONCLUSION}

In conclusion, the width of the printed pattern influences the resistivity, as resistance increases with decreasing width of the line. This creates challenges in downscaling an integrated circuit. Therefore, intensive studies are required to keep pace with future demands. The electromechnical performance was examined in four different patterns: straight, sinusoidal, square and zig-zag. The printed circuit showed its ability to accommodate stretching up to a strain of $7.78 \%$ using $3 \mathrm{~mm}$ width of zig-zag pattern. However, the value is still insufficient for it to be integrated into the daily application. Further studies are needed to investigate ink characterisation such as silver composition percentage and curing temperature variation as these variables affect the performance of the pattern. Besides that, performing 3D Finite Element Analysis (FEA) in future studies to capture the thermo-mechanical modelling of sample patterns would show clearer distribution of stress or strain in specific parts of the structure for better analysis and understanding.

\section{ACKNOWLEDGEMENTS}

The authors would like to acknowledge Universiti Teknikal Malaysia Melaka, Malaysia for the UTeM Zamalah Scheme 2.0 scholarship, the Ministry of Education (MoE), Malaysia under Fundamental Research Grant Scheme (FRGS, grant no. FRGS/2018/FKM-CARE/F00366) and the Advance Material Characterization (AMCHAL) that make this study possible.

\section{REFERENCES}

1. Zhang, G. Q., Van Driel, W. D. \& Fan, X. J. (2006). Mechanics of microelectronics. Amsterdam: Springer Science \& Business Media.

2. Younis, M. I. (2004). Modeling and simulation of microelectromechanical systems in multi-physics fields. PhD diss., Virginia Tech.

3. Coombs, C. F. \& Holden, H. T. (2001). Printed circuits handbook. New York: McGraw-Hill.

4. Khan, S., Lorenzelli, L. \& Dahiya, R. S. (2014). Technologies for printing sensors and electronics over large flexible substrates: A review. IEEE Sens. J., 15(6), 3164-3185. https://doi.org/10.1109/JSEN.2014.2375203

5. Pease, R. F. \& Chou, S. Y. (2008). Lithography and other patterning techniques for future electronics. P. IEEE, 96(2), 248-270. https://doi.org/10.1109/JPROC .2007 .911853

6. Søndergaard, R. R., Hösel, M. \& Krebs, F. C. (2013). Roll-to-roll fabrication of large area functional organic materials. J. Polym. Sci. Pol. Phys., 51(1), 16-34. 
7. Tobjörk, D. \& Österbacka, R. (2011). Paper electronics. Adv. Mater., 23(17), 1935-1961. https://doi.org/10.1002/polb.23192

8. Mohammed, A. \& Pecht, M. (2016). A stretchable and screen-printable conductive ink for stretchable electronics. Appl. Phys. Lett., 109(18), 184101. https://doi.org/10.1063/1.4965706

9. Nir, M. M. et al. (2010). Electrically conductive inks for inkjet printing. In Magdassi, S. (Ed.), The chemistry of inkjet inks. New York: World Scientific Publishing, 356-371.

10. Merilampi, S., Laine-Ma, T. \& Ruuskanen, P. (2009). The characterisation of electrically conductive silver ink patterns on flexible substrates. Microelectron. Reliab., 49(7), 782-790. https://doi.org/10.1016/j.microrel.2009.04.004

11. Kim, J. et al. (2017). Advanced materials for printed wearable electrochemical devices: A review. Adv. Electron. Mater., 3(1), 1600260. https://doi.org/10.1002/ aelm. 201600260

12. Liang, J. et al. (2009). Electromagnetic interference shielding of graphene/epoxy composites. Carbon, 47(3), 922-925. https://doi.org/10.1016/j.carbon.2008.12.038

13. Sandler, J. K. W. et al. (2003). Ultra-low electrical percolation threshold in carbonnanotube-epoxy composites. Polym., 44, 5893-5899. https://doi.org/10.1016/ S0032-3861(03)00539-1

14. Lin, Y. S. \& Chiu, S. S. (2008). Electrical properties of copper-filled electrically conductive adhesives and pressure-dependent conduction behavior of copper particles. J. Adhes. Sci. Technol., 22(14), 1673-1697. https://doi.org/10.1163/ $156856108 \times 320537$

15. Lee, H. H., Chou, K. S. \& Shih, Z. W. (2005). Effect of nano-sized silver particles on the resistivity of polymeric conductive adhesives. Int. J. Adhes. Adhes., 25(5), 437-441. https://doi.org/10.1016/j.ijadhadh.2004.11.008

16. Suzuki, M., Takahashi, T. \& Aoyagi, S. (2012). Flexible tactile sensor using polyurethane thin film. Micromach., 3(2), 315-324. https://doi.org/10.3390/ mi3020315

17. Caglar, U., Kaija, K. \& Mansikkamaki, P. (2008). Anlaysis of mechanical performance of silver inkjet-printed structures. Paper presented at the 2nd IEEE International Nanoelectronics Conference, Shanghai, 24-27 March, 851-856.

18. Dziedzic, A. (2007). Carbon/polyesterimide thick-film resistive compositesexperimental characterisation and theoretical analysis of physicochemical, electrical and stability properties. Microelectron. Reliab., 47(2-3), 354-362. https://doi.org/10.1016/j.microrel.2006.02.016

19. Lin, Y. S. \& Chiu, S. S. (2004). Effects of oxidation and particle shape on critical volume fractions of silver-coated copper powders in conductive adhesives for microelectronic applications. Polym. Eng. Sci., 44(11), 2075-2082. https://doi.org/10.1002/pen.20212

20. Park, S., Vosguerichian, M. \& Bao, Z. (2013). A review of fabrication and applications of carbon nanotube film-based flexible electronics. Nanosc., 5(5), 1727-1752. https://doi.org/10.1039/C3NR33560G 
21. Harris, K. D., Elias, A. L. \& Chung, H. J. (2016). Flexible electronics under strain: a review of mechanical characterisation and durability enhancement strategies. J. Mater. Sci., 51(6), 2771-2805. https://doi.org/10.1007/s10853-015-9643-3

22. Abu-Khalaf, J. et al. (2018). Experimental characterisation of inkjet-printed stretchable circuits for wearable sensor applications. Sensors, 18(10), 3476. https://doi.org/10.3390/s18103476

23. Gonzalez, M. et al. (2008). Design of metal interconnects for stretchable electronic circuits. Microelectron. Reliab., 48(6), 825-832. https://doi.org/10 .1016/j.microrel.2008.03.025

24. Agarwala, S., Goh, G. L. \& Yeong, W. Y. (2018). Aerosol jet printed strain sensor: Simulation studies analysing the effect of dimension and design on performance. IEEE Access, 6, 63080-63086. https://doi.org/10.1109/ACCESS.2018.2876647

25. Long, X. et al. (2019). Correlation of microstructure and constitutive behaviour of sintered silver particles via nanoindentation. Int. J. Mech. Sci., 161-162, 105020. https://doi.org/10.1016/j.ijmecsci.2019.105020

26. Maîtrejean, S. et al. (2006). Experimental measurements of electron scattering parameters in $\mathrm{Cu}$ narrow lines. Microelectron. Eng., 83(11-12), 2396-2401. https://doi.org/10.1016/j.mee.2006.10.044

27. Choi, S. et al. (2018). Effect of metal line width on electromigration of BEOL Cu interconnects. Paper presented at the 2018 IEEE International Reliability Physics Symposium (IRPS), Burlingame, CA, 11-15 March.

28. Hu, C. K. et al. (2013). Materials and scaling effects on on-chip interconnect reliability. MRS Online Proceed. Libr. Arch., 1559. https://doi.org/10.1557/ opl.2013.872

29. Lu, N. et al. (2007). Metal films on polymer substrates stretched beyond $50 \%$. Appl. Phys. Lett., 91(22), 221909. https://doi.org/10.1063/1.2817234

30. Lacour, S. P. et al. (2003). Stretchable gold conductors on elastomeric substrates. Appl. Phys. Lett., 82(15), 2404-2406. https://doi.org/10.1063/1.1565683 